\title{
Morphological Evaluation of Wound Healing Events in the Excisional Wound Healing Model in Rats
}

Lígia Reis de Moura Estevão, ${ }^{1,}$ Puebla Cassini-Vieira² ${ }^{2}$ Ana Greice Borba Leite ${ }^{1}$, Apolônia Agnes Vilar de Carvalho Bulhões ${ }^{1}$, Lucíola da Silva Barcelos ${ }^{3}$ and Joaquim Evêncio-Neto ${ }^{1}$

${ }^{1}$ Department of Morphology and Animal Physiology, Universidade Federal Rural de Pernambuco (UFRPE), Recife-PE, Brazil; 2Department of Medicine, Division of Hematology/Oncology Department of Immunology and Microbiology, Cancer Center Rush University Medical Center, Chicago, USA; ${ }^{3}$ Department of Physiology and Biophysics (ICB) Universidade Federal de Minas Gerais (UFMG), Belo Horizonte-MG, Brazil

*For correspondence: ligiarme@yahoo.com.br

[Abstract] Skin wound healing is a complex process involving different events such as blood coagulation, inflammation, new blood vessels formation, and extracellular matrix deposition. These events can be observed by using histology techniques. However, the lack of the standardization of such parameters impacts on the reproducibility of results. Here, we describe a protocol to perform macroscopic and microscopic analyses of the events that occur during skin wound healing using the experimental model of excisional wounds in rats.

Keywords: Rat excisional wound, Histological score, Angiogenesis, Inflammation, Collagen deposition, Epithelialization

[Background] Skin wounds can be induced by extrinsic factors such as surgical incision, accidental injury or trauma, or by intrinsic factors such as those produced by infection and chronic ulcers. The skin wound healing is a complex process involving cellular, molecular and humoral components to tissue reestablishment after injury. In healthy adult mammals, it involves an early inflammatory phase, characterized by infiltration of leucocytes, with subsequent formation of granulation tissue (new tissue formed), epithelization, and matrix remodeling (Balbino et al., 2005; Estevão et al., 2017). An accurate assessment of wound healing events is critical to reproducible data, with histological studies being the gold standard in this area of knowledge. Here, we describe a protocol using an excisional wound healing model in rats to demonstrate the wound creation, wound closure evaluation and qualitative analysis of microscopic events (inflammation, extracellular matrix deposition, angiogenesis, and epithelialization) in skin wounds.

\section{Materials and Reagents}

1. Glass slides (Micro Slides, VWR, catalog number: 48311-703)

2. Coverslip slides (IMEB, catalog number: CG1-2450)

3. Wistar rats (Rattus norvergicus albinus), $250-300 \mathrm{~g}$, and $90-100$ days old 
4. Paraffin (Fisher Scientific, catalog number: AC416770020)

5. Ketamine hydrochloride (Sigma, catalog number: K113)

6. Xylazine hydrochloride (Sigma, catalog number: K4138)

7. Formaldehyde (Fisher Scientific, catalog number: SF100-4)

8. Ethanol (Fisher Scientific, catalog number: BP2818100)

9. Xylene (Fisher Scientific, catalog number: X3S-4)

10. Xylene-based mounting medium (Source Mount, catalog number: 9277722)

11. Hematoxylin (Merck, catalog number: 517-28-2)

12. Potassium alum (Merck, catalog number: 7784-24-9)

13. Mercury oxide (Merck, catalog number: 21908-53-2)

14. Eosin (Merck, catalog number: 15086-94-9)

15. Phloxine B (Merck, catalog number: 18472-87-2)

16. Acetic Acid (Merck, catalog number: 64-19-7)

17. Sodium phosphate dibasic (Merck, catalog number: 7558-79-4)

18. Sodium phosphate monobasic (Merck, catalog number: 7558-80-7)

19. Phosphotungstic acid hydrate (Merck, catalog number: 12501-23-4)

20. Chromotrope 2R (Merck, catalog number: 4197-07-4)

21. Fast green FCF (Merck, catalog number 2353-45-9)

22. Harris Hematoxylin (see Recipes)

23. Eosin (stock solution) (see Recipes)

24. Eosin phloxine (see Recipes)

25. $10 \%$ buffered formaldehyde (see Recipes)

26. Gomori (see Recipes)

\section{Equipment}

1. Digital caliper (Digimess, King Tools, catalog number: $502.150 \mathrm{BL}$ )

2. Hair removal machine (Wahl and Toshico)

3. Tweezers $14 \mathrm{~cm}$ (Golgan, Fibra cirúrgica, catalog number: 003439)

4. Straight Metzenbaum Scissors (WPI, catalog number: 501747)

5. $8 \mathrm{~mm}$ diameter circular biopsy punch (Kruuse, catalog number: 273693)

6. $10 \mathrm{~mm}$ diameter circular biopsy punch (Integra Miltex, catalog number: $12-460-406$ )

7. LEICA ${ }^{\circledR}$ manual microtome (LEICA, model: M2125RT)

8. Trinocular Microscope with HD camera (LEICA, model: DM500)

9. Histological Bath (Lupetec, model: BH2015) 


\section{Procedure}

A. Excisional skin wounds in rats (Figure 1)

1. Anesthetize the animal with an intramuscular injection with a mixture of ketamine and xylazine (20 mg/kg and $100 \mathrm{mg} / \mathrm{kg}$, respectively) or following the requirements from the local ethics committee.

2. Shave the dorsal region and gently remove two fragments from the skin using an $8 \mathrm{~mm}$ diameter circular biopsy punch (the distance between wounds should be approximately $1.5 \mathrm{~cm})$.

Note: This procedure should be handled carefully to not damage the muscular layer below the skin.

3. Measure the wound area immediately using a digital caliper and repeat the procedure on Days $3,7,14$ and 21 after wound creation.

Note: This time-course corresponds virtually with phases of skin healing processes.
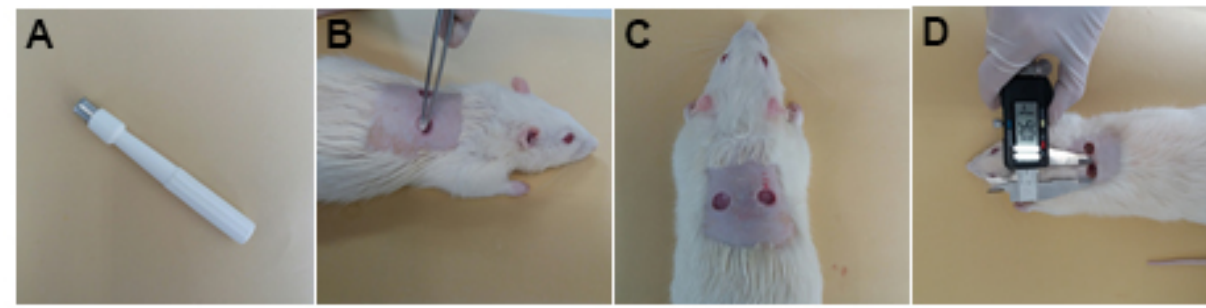

Figure 1. Skin wound creation in rats. A. 8-mm diameter biopsy punch. B-C. Remove two fragments from the dorsal skin. D. Wound area measurement using a digital caliper.

B. Histological evaluation of wounds

1. Euthanize the animals on Days $3,7,14$ and 21 after wound creation. This procedure must be in agreement with protocols approved by the local ethical committee.

2. Collect the skin fragments using a $10 \mathrm{~mm}$ punch. It should cover the entire wound area.

3. Immediately fix the skin fragments in $10 \%$ buffered formaldehyde. After $6 \mathrm{~h}$ in fixation solution, cleaves the tissues in half using a razor and keep the tissues in fixation solution for $24 \mathrm{~h}$. It is crucial to establish the cleave orientation for all wounds (craniocaudal or later-lateral direction), as showing in Figure 2.

Note: For longer-term storage, after $24 \mathrm{~h}$ transfer the fragments to $70 \%$ ethanol.

4. Use routine procedures for processing paraffin embedding tissues (dehydration, clearing and wax infiltration).

a. Dehydration

90\% ethanol: $30 \mathrm{~s}$

$100 \%$ ethanol I: $30 \mathrm{~s}$

100\% ethanol II: $30 \mathrm{~s}$ 


\section{bĭo-protocol}

b. Clearing (Diaphanization)

Xylol I: $30 \mathrm{~s}$

Xylol II: $30 \mathrm{~s}$

c. Wax infiltration (Inclusion in paraffin) in a regulated oven at $59^{\circ} \mathrm{C}$

Paraffin I: $30 \mathrm{~s}$

Paraffin II: $30 \mathrm{~s}$

d. Embedding

The infiltrated tissue should be placed into the base mold with skin sectioned surface facing down (Figure 2C).
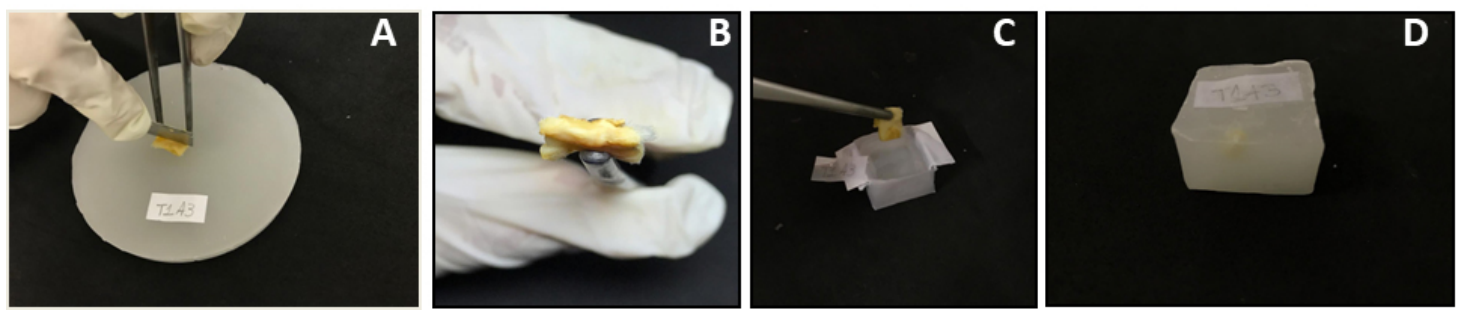

Figure 2. Cleavage and embedding wound tissues. A. Cleavage of paraffin infiltrated tissue;

B. Cleaved surface; C. Placing the cleaved surface tissue in a base mold; D. Wax block.

5. Sectioning of paraffin-embedded tissue

a. Place the wax block on the microtome with its surface parallel to the blade.

b. Cut sections at a thickness of about 4-5 $\mu \mathrm{m}$.

c. Use tweezers to pick up the sectioned tissues and transfer to the $39{ }^{\circ} \mathrm{C}$ water bath.

d. Take the floating sections using glass slides (Figure 3).

e. Slides can be stored in racks in an upright position, then dried in an oven, however not exceed $65^{\circ} \mathrm{C}$.

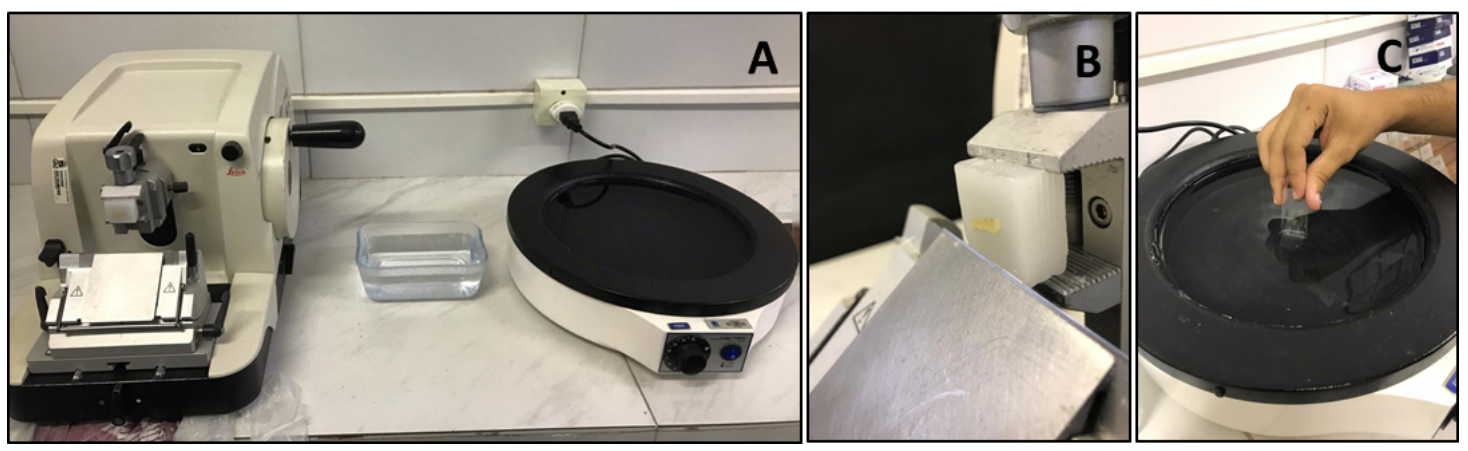

Figure 3. Sectioning procedure using microtome. A. Manual microtome and histological bath. B.

Place and adjust the wax block. C. Collect the sectioned tissue with a clean and identified glass slide. 
6. Hematoxylin and Eosin (H\&E) and Gomori's trichrome staining

a. Hematoxylin-Eosin staining

See preparation of solutions (Recipes): Harris Hematoxylin and Eosin Phloxine Technique:

Xylene I and xylene II

5 min each

$100 \%$ ethanol

$1 \mathrm{~min}$

$90 \%$ ethanol

$1 \mathrm{~min}$

$70 \%$ ethanol

3 min

Rinse in distilled water

$1 \mathrm{~min}$

Hematoxylin

$30 \mathrm{~s}$ to $1 \mathrm{~min} 30 \mathrm{~s}$

Tap water

$10 \mathrm{~min}$

Eosin phloxine

1-3 min

$70 \%$ ethanol

count 10 times

90\% ethanol count 10 times

$100 \%$ ethanol I

$1 \mathrm{~min}$

$100 \%$ ethanol II

$1 \mathrm{~min}$

Xylene I

$3 \mathrm{~min}$

Xylene II

3 min

b. Gomori trichrome staining

$\begin{array}{ll}\text { Xylene I and xylene II } & 5 \text { min each } \\ 100 \% \text { ethanol } & 1 \mathrm{~min} \\ 90 \% \text { ethanol } & 1 \mathrm{~min} \\ 70 \% \text { ethanol } & 3 \mathrm{~min} \\ \text { Rinse in distilled water } & 1 \mathrm{~min} \\ \text { Harris Hematoxylin } & 30 \mathrm{~s} \text { to } 1 \mathrm{~min} 30 \mathrm{~s} \\ \text { Rinse under tap water } & 10 \mathrm{~min} \\ \text { Gomori trichrome dye } & 15-20 \mathrm{~min} \\ \text { Rinse in distilled water with } 0.5 \% \text { acetic acid } & 2 \mathrm{~min} \\ 95 \% \text { ethanol I } & \text { count } 10 \text { times } \\ 95 \% \text { ethanol II } & 1 \mathrm{~min} \\ 100 \% \text { ethanol I } & 1 \mathrm{~min} \\ 100 \% \text { ethanol II } & 1 \mathrm{~min} \\ \text { Xylene I } & 3 \mathrm{~min} \\ \text { Xylene II } & 3 \mathrm{~min}\end{array}$

7. The morphological analyses are performed on new tissue in formation and, at later time-points, on the formed cicatricial tissue. Six fields per slice should be evaluated to encompass the borders (area of boundary between the intact connective tissue and the one in formation) and the center of the wound or the scar. For each parameter, five slices are analyzed. 
8. The qualitative histology studies should be performed by analyzing the stained tissues using a specific score for each parameter, according to described below:

\section{Inflammation}

Evaluate the cellular infiltration (polymorphonuclear and mononuclear) in HE-stained sections using the 10x objective (Table 1 and Figure 4).

Table 1. Morphological scores of inflammation in H\&E-stained histological sections of excisional rat wounds

\begin{tabular}{ll}
\hline Score & Parameter \\
\hline 0 & WHOLE SKIN-absence of inflammation \\
\hline 1 & DISCRETE-presence of few inflammatory cells \\
\hline 2 & MODERATE-many inflammatory cells \\
\hline 3 & SEVERE-exaggerated inflammatory cellularity \\
\hline
\end{tabular}
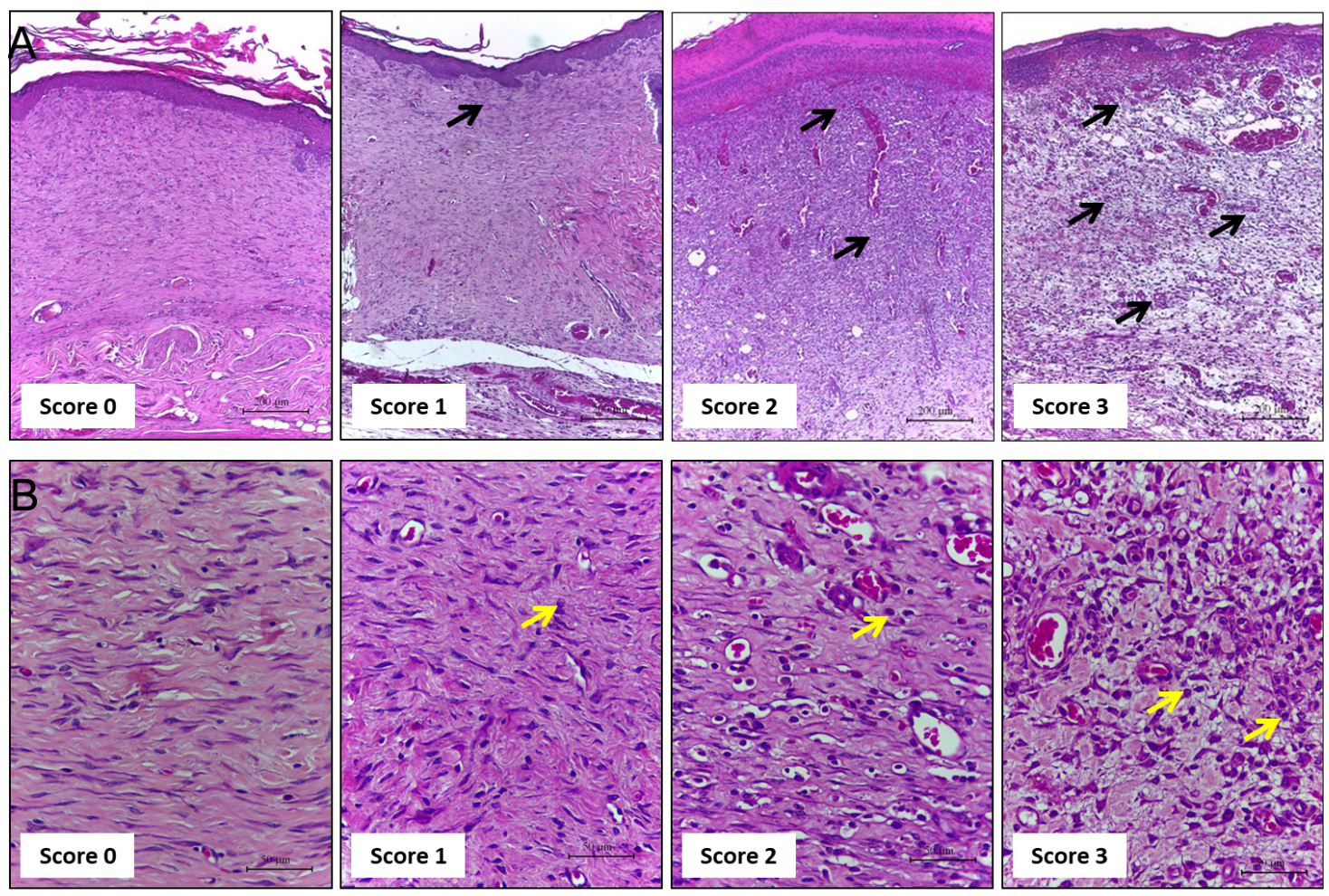

Figure 4. Representative photomicrographs of sections stained with $\mathrm{H}$ \& E showing the inflammation score. Score 0: skin; Score 1: the wound of Days 21 and 14; Score 2: on Day 7 , score 3: on Day 3. Inflammatory cells indicated by black and yellow arrows at different concentrations according to the healing time. A. Scale bars: $200 \mu \mathrm{m}$ B. Scale bars: $50 \mu \mathrm{m}$. 


\section{Scab}

Evaluate the amount of scab formed in the wound tissue by HE-stained sections analysis using the $4 \mathrm{x}$ objective (Table 2 and Figure 5).

Table 2. Morphological scores of scab in H\&E-stained histological sections of excisional rats wounds

\begin{tabular}{ll}
\hline Score & Parameter \\
\hline 0 & ABSENCE \\
\hline 1 & DISCRETE \\
\hline 2 & MODERATE \\
\hline 3 & SEVERE \\
\hline
\end{tabular}
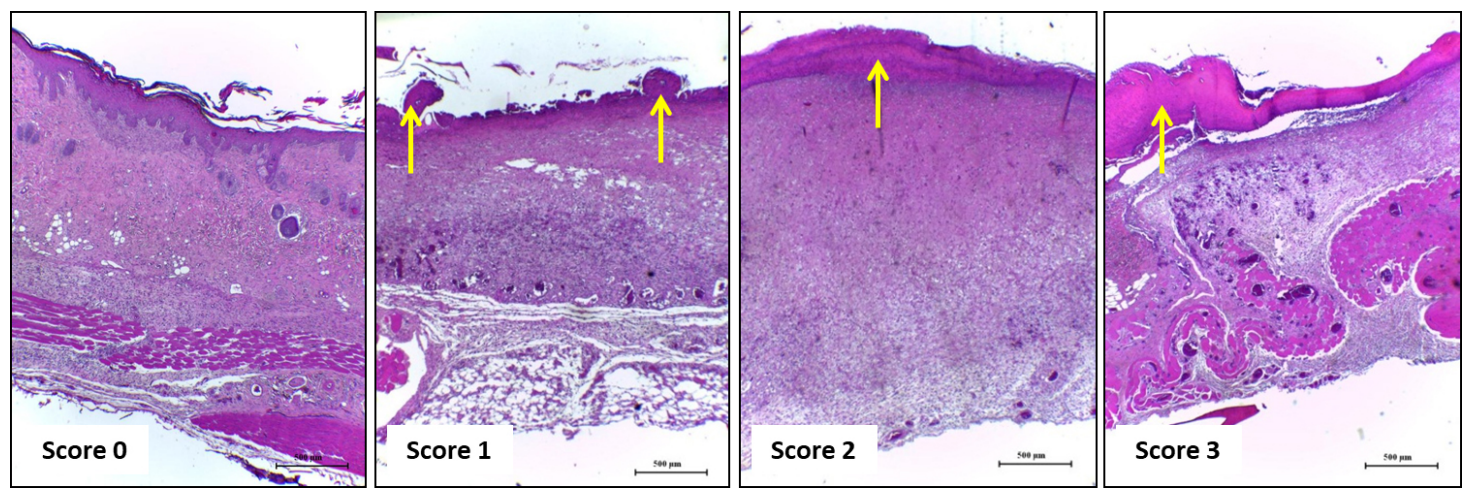

Figure 5. Representative photomicrographs of H\&E stained sections showing the scores of scab. Scores 0: on Day 21; Score 1: on Day 14, Score 2: on Day 7 or 3, Score 3: on Day 3 or 7 . Scale bars: $500 \mu \mathrm{m}$.

\section{Extracellular matrix deposition}

Evaluate the amount of extracellular matrix deposited, and the thickness of collagen fibers in Gomori's trichrome-stained sections using the 10x objective (Table 3 and Figure 6).

Table 3. Morphological scores of extracellular matrix deposition in Gomori's trichrome-stained histological sections of excisional rat wounds

\begin{tabular}{ll}
\hline Score & Parameter \\
\hline 0 & WHOLE SKIN-whole extracellular matrix \\
\hline 1 & $\begin{array}{l}\text { DISCRETE-incomplete presence of extracellular matrix (identified by } \\
\text { many fibroblasts, and thin collagen fibers) }\end{array}$ \\
\hline 2 & $\begin{array}{l}\text { MODERATE-presence of extracellular matrix in the whole wound area } \\
\text { (identified by many fibroblasts, and thin collagen fibers) }\end{array}$ \\
\hline 3 & HIGH-presence of extracellular matrix in the whole wound area (identified \\
by few fibroblasts, and thick collagen fibers)
\end{tabular}



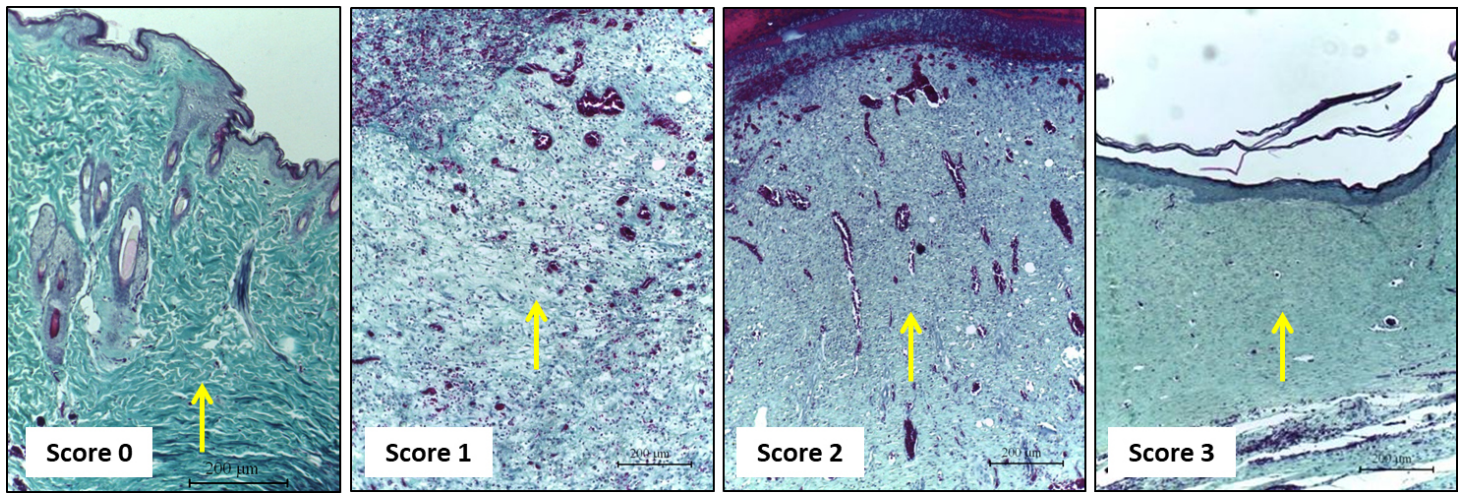

Figure 6. Representative photomicrographs of Gomori's trichrome-stained sections showing the score of extracellular matrix deposition. Score 0: skin; Score 1: on Day 3; Score 2: on Day 7, Score 3: on Day 14 and Day 21. Scale bars: $200 \mu \mathrm{m}$.

\section{Vascularization}

Evaluate the amount of blood vessels in the new tissue formed in HE-stained sections using the $40 x$ objective (Table 4 and Figure 7 ).

Table 4. Morphological scores of vascularization in H\&E-stained histological sections of excisional rats wounds

\begin{tabular}{ll}
\hline Score & Parameter \\
\hline 0 & WHOLE SKIN-normal vascularization \\
\hline 1 & DISCRETE VASCULAR FORMATION \\
\hline 2 & MODERATE VASCULAR FORMATION \\
\hline 3 & HIGH VASCULAR FORMATION
\end{tabular}
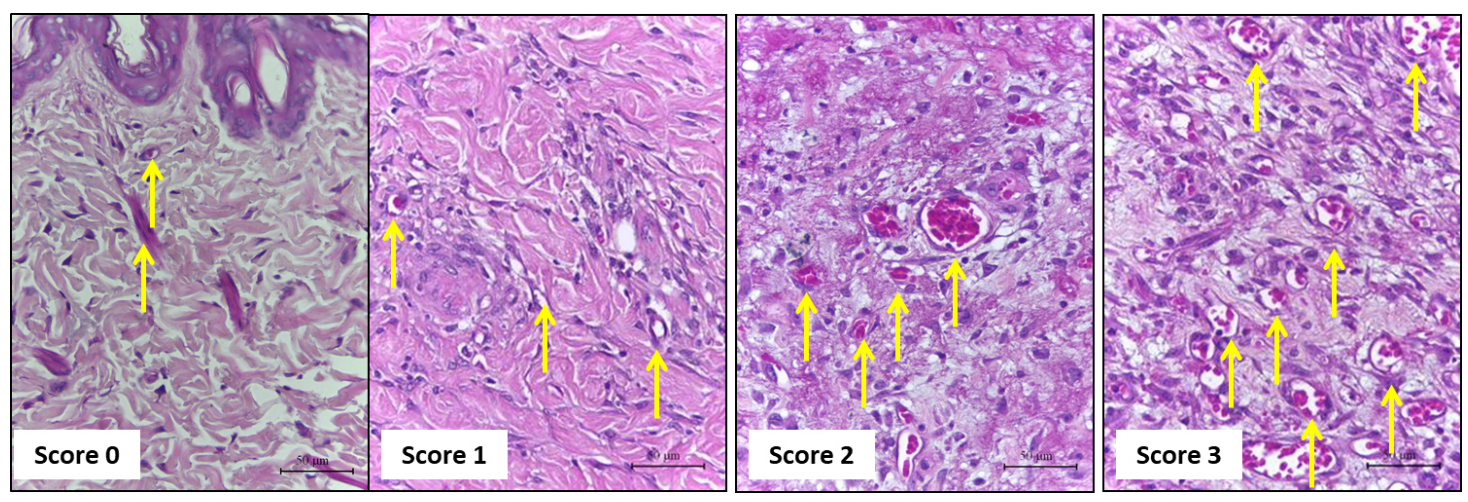

Figure 7. Representative photomicrographs of H\&E stained sections showing the score of vascularization. Score 0: whole skin; Scores 1: on Day 21; Score 2: on Day 14, Score 3: on Days 3 and 7 . Scale bars: $50 \mu \mathrm{m}$. 


\section{Epithelialization}

Evaluate the new epithelial layer formed in HE-stained sections using the 10x objective (Table 5 and Figure 8).

Table 5. Morphological scores of epithelialization in H\&E-stained histological sections of excisional rat wounds

\begin{tabular}{ll}
\hline Score & Parameter \\
\hline 0 & WHOLE SKIN-whole epithelium \\
\hline 1 & $\begin{array}{l}\text { DISCRETE-partial epithelization with a small new epithelial layer (the } \\
\text { epithelial tongue occupies, at most, } 1 / 3 \text { of the wound gap) }\end{array}$
\end{tabular}

2

MODERATE-partial epithelization with a longer new epithelial layer (the epithelial tongue occupies more than $1 / 3$ of the wound gap)
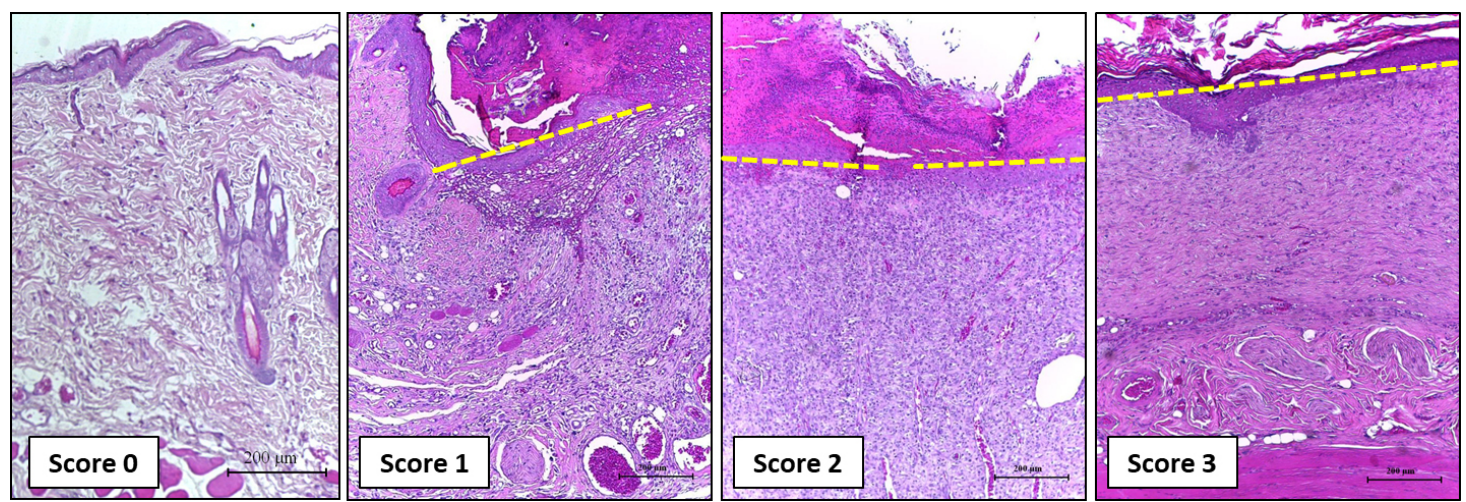

Figure 8. Representative photomicrographs of H\&E stained sections showing the wound epithelialization score. Scores 0: on Day 3; Score 1: on Day 7, Score 2: on Day 14, Score 3: on Day 21. Scale bars: $200 \mu \mathrm{m}$.

\section{$\underline{\text { Data analysis }}$}

For each parameter, the data analysis is performed using the mean of the score from each slice analyzed (Figure 9). 


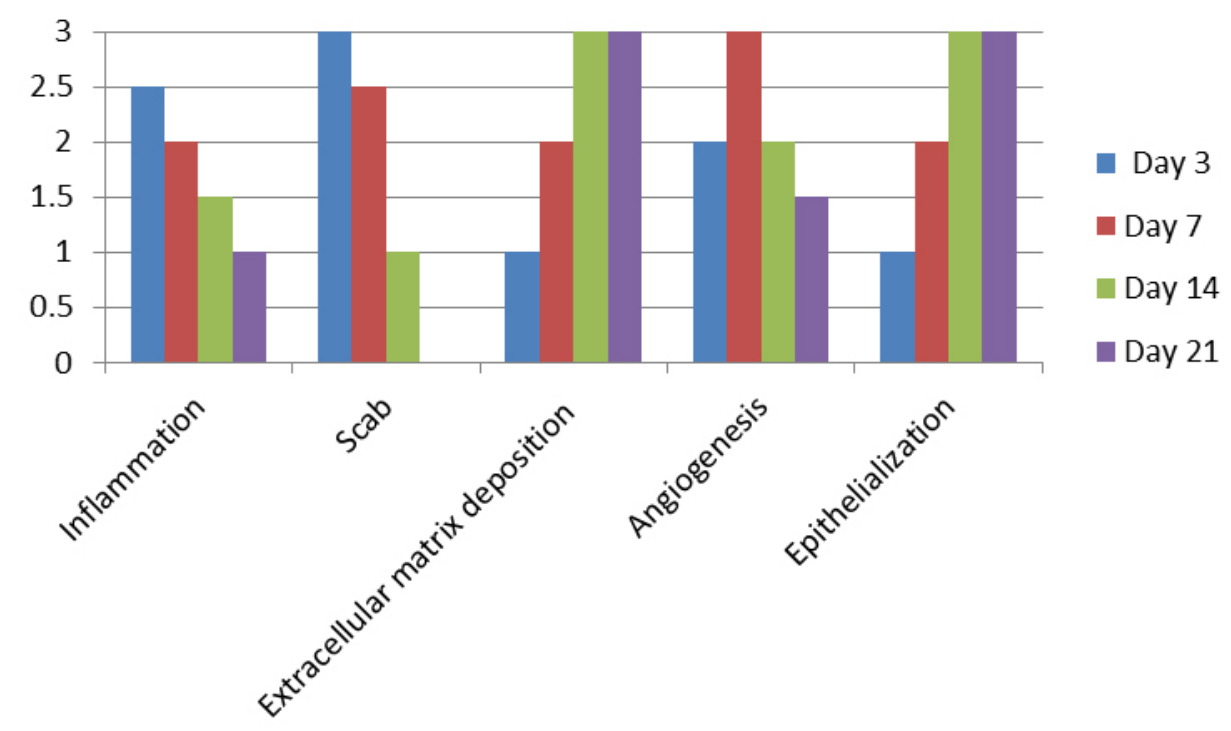

Figure 9. Predictable scores for each parameter on Days 3, 7, 14, and 21 after wound confection in healthy Wistar rats. Inflammation: It occurs at the beginning of the healing process with plasma extravasation, platelet aggregation, clot formation and recruitment of inflammatory (polymorphonuclear and mononuclear) cells to the wound site. Scab: Formed from cellular debris, fibrin, and red blood cells; remain as the epithelial tongue fills the injured site with epithelium. Extracellular matrix deposition: In a second phase, the fibroblasts are in charge of producing collagen fibers and filling the injured area, along with leucocytes and blood vessels, forming the granulation tissue. These fibers will be remodeling and polymerizing until the end of the healing, becoming increasingly dense and organized. Angiogenesis: accompanies the stage of inflammation and fibroplasia, peaking at 5-7 days. Epithelialization: In excisional wounds, these cells depart from the edges of the injured epithelium towards the center of the wound until they are joined and cover the whole site of the epithelium (Balbino et al., 2005; Abbas et al., 2010; Moreira et al., 2015).

\section{$\underline{\text { Notes }}$}

1. For reproducibility, the measurement of the wound area must be performed by a single observer throughout the experimental time.

2. For histological analysis, after collection of the wound tissue, place the wound on a piece of filter paper to avoid tissue folding during the fixation process in $10 \%$ buffered formaldehyde. Then proceed to conventional paraffin embedding processes.

3. The cicatricial process can last for months in the remodeling phase, being able to be evaluated in time-points longer than 21 days, according to the experimental aim.

4. The pictures indicated for each score correspond to cutaneous wounds of $8 \mathrm{~mm}$ that cure spontaneously in healthy rats.

5. See Castro-Souza et al. (2017) for details on how to analyze the wound area. 
6. See Moreira et al. (2015) for details on excisional skin wounds.

\section{Recipes}

1. Harris Hematoxylin

$\begin{array}{ll}\text { Hematoxylin } & 5.0 \mathrm{~g} \\ \text { Alcohol 96\% } & 50 \mathrm{ml} \\ \text { Potassium alum } & 100 \mathrm{~g} \\ \text { Distilled water } & 1,000 \mathrm{ml} \\ \text { Mercury oxide } & 2.5 \mathrm{~g} \\ \text { Glacial acetic acid } & 4 \mathrm{ml}\end{array}$

Dissolve hematoxylin in alcohol; Dissolve the potassium alum in the heated water (do not boil); mix the two solutions; boil quickly ( $1 \mathrm{~min}$ ); slowly add the mercury oxide; let it simmer until it turns purple; remove from heating and put in cold water bath; Add acetic acid; Store in an amber bottle and filter before use

2. Eosin (stock solution)

Eosin $Y$

Distilled water

3. Eosin Phloxine

Aqueous Eosin 1\%

Ethanol 95\%

Phloxine B $1 \%$ in distilled water

Glacial acetic acid

4. $10 \%$ buffered formaldehyde

Phosphate buffer, 0.2 M, pH 7.2-7.4

$\mathrm{Na}_{2} \mathrm{HPO}_{4}$ (sodium phosphate dibasic)

$\mathrm{NaH}_{2} \mathrm{PO}_{4}$ sodium phosphate monobasic)

Distilled water

Adjust the $\mathrm{pH}$ and fill the volume to

$37 \%$ formaldehyde

Phosphate buffer

5. Gomori

Chromótrope 2R

Fast greem FCF

Phosphotungstic acid hydrate

Glacial acetic acid

Distilled water

\section{$1.0 \mathrm{~g}$}

$100 \mathrm{ml}$

$100 \mathrm{ml}$

$780 \mathrm{ml}$

$10 \mathrm{ml}$

$4 \mathrm{ml}$

$11.155 \mathrm{~g}$

$2.767 \mathrm{~g}$

$400 \mathrm{ml}$

$500 \mathrm{ml}$

$100 \mathrm{ml}$

$900 \mathrm{ml}$

$0.6 \mathrm{~g}$

$0.3 \mathrm{~g}$

$0.8 \mathrm{~g}$

$1.0 \mathrm{ml}$

$100 \mathrm{ml}$ 


\section{Acknowledgments}

This work was supported by Conselho Nacional de Pesquisa/CNPq, Coordenação de Aperfeiçoamento de Pessoal de Nível Superior/CAPES, Fundação de Amparo à Ciência e Tecnologia de Pernambuco- FACEPE, Programa de Biociência Animal da UFRPE, Recife, PE, Brazil. LRME holds a CAPES PNPD scholarship; LSB and JEN hold CNPq Research Fellowships. The funders had no role in study design, data collection and analysis, decision to publish, or preparation of the manuscript.

\section{Ethics}

The project proposal was approved by the Animal Ethics Committee of the Universidade Federal Rural University de Pernambuco (license no 57/2017). At the end of the experiment the animals were euthanized, prepared and discarded complied with the guidelines established by our local Institutional Animal Welfare Committee.

\section{References}

1. Abbas, A., Kumar, V., Fausto, N (2010). Robbins \& Cotran -Patologia - Bases Patológicas das Doenças. $8^{a}$ ed. Rio de Janeiro: Elsevier. 1557p.

2. Balbino, C. A., Pereira, L. M. and Curi, R. (2005). Mechanisms involved in wound healing: a revision. Rev Bras Cienc Farm 41(1): 27-51.

3. Castro Souza Junior Neto, J., Estevao, L. R., Baratella-Evencio, L., Vieira, M. G., Simoes, R. S., Florencio-Silva, R., Evencio-Luz, L. and Evencio-Neto, J. (2017). Mast cell concentration and skin wound contraction in rats treated with Ximenia americana L. Acta Cir Bras 32(2): 148-156.

4. Estevão, L. R. M., Simões, R. S., Cassini-Vieira, P., Canesso, M. C. C., Barcelos, L. D. S., Rachid, M. A., Camara, C. and Evêncio-Neto, J. (2017). Schinus terebinthifolius Raddi (Aroeira) leaves oil attenuates inflammatory responses in cutaneous wound healing in mice. Acta Cir Bras 32(9): 726-735.

5. Moreira, C. F., Cassini-Vieira, P., Silva, M. F. and Barcelos, L.S. (2015). Skin wound healing model - excisional wounding and assessment of lesion area. Bio-protocol 5(22): e1661. 